REVUE DE L'INSTITUT

FRANC AIS D'HISTOIRE

EN ALLEMAGNE

\section{Revue de I'IFHA}

Revue de l'Institut français d'histoire en Allemagne

$6 \mid 2014$

IFHA 6

\title{
La littérature illustrée pour enfants à l'époque de la Première Guerre mondiale. Origines et évolution de la culture de guerre enfantine allemande
}

Bérénice Zunino

\section{CpenEdition}

Journals

Édition électronique

URL : http://journals.openedition.org/ifha/8062

DOI : 10.4000/ifha.8062

ISSN : 2198-8943

Éditeur

IFRA - Institut franco-allemand (sciences historiques et sociales)

Édition imprimée

Date de publication : 31 décembre 2014

ISSN : 2190-0078

Référence électronique

Bérénice Zunino, « La littérature illustrée pour enfants à l'époque de la Première Guerre mondiale. Origines et évolution de la culture de guerre enfantine allemande », Revue de l'IFHA [En ligne], 6 | 2014, mis en ligne le 31 décembre 2014, consulté le 30 avril 2019. URL : http://journals.openedition.org/ ifha/8062 ; DOI : 10.4000/ifha.8062

Ce document a été généré automatiquement le 30 avril 2019

(CIFHA 


\title{
La littérature illustrée pour enfants à l'époque de la Première Guerre mondiale. Origines et évolution de la culture de guerre enfantine allemande
}

\author{
Bérénice Zunino
}

\section{NOTE DE L'ÉDITEUR}

Thèse de doctorat en cotutelle sous la direction de Jean-Paul Cahn et Oliver Janz, Université Paris-Sorbonne et Freie Universität Berlin, dont la soutenance se tiendra le 12 décembre à Paris.

1 Dans une perspective d'histoire culturelle, cette thèse, fondée sur une approche iconologique, se propose de montrer, à partir de l'exemple de la littérature illustrée, que la culture de guerre enfantine allemande n'apparut pas ex nihilo en 1914. Elle avait ses racines dans la culture mémorielle d'avant-guerre, centrée sur une glorification des faits d'armes. Issu de la peinture historique, un imaginaire héroïque, qui faisait appel à des réflexes émotionnels, en constituait les fondements. La guerre provoqua une intensification et un épanouissement de la culture de guerre.

2 La comparaison des programmes éditoriaux de deux maisons d'édition, Josef Scholz (Mayence) et Ferdinand Schreiber (Esslingen) nous a permis de proposer une approche différenciée et nuancée de la culture de guerre. Facteur d'intensification de leur production patriotique pour certains éditeurs, le conflit marqua une rupture plus nette pour d'autres entreprises. Les éditeurs s'adaptèrent progressivement au conflit et ne commercialisèrent véritablement les livres patriotiques que pour les fêtes de Noël 1914. Alors que la plupart des fronts s'étaient enlisés, faisant place à une guerre de position, ces 
ouvrages continuèrent à véhiculer l'image familière et rassurante d'une guerre de mouvement.

À mesure que les hostilités duraient, des dessins kitsch aux motifs enfantins et des caricatures de l'ennemi firent leur entrée dans les albums : ils étaient propices à justifier le conflit, stylisé en une guerre défensive. Ces strates ludiques de la culture de guerre enfantine, qui provenaient de l'iconographie politique pour adultes datant du XIXe siècle, favorisèrent un élargissement du lectorat, auparavant scolaire, aux jeunes enfants dès l'âge de trois ans, et paradoxalement une prise en compte de certaines exigences des représentants de la pédagogie réformée, prônant une éducation plus adaptée à l'esprit enfantin.

Les auto-images valorisantes l'emportèrent toutefois sur la haine et la ridiculisation de l'ennemi. Conjointement aux caricatures, les portraits apologétiques des dirigeants et l'émergence timide d'une iconographie $d u$ "combattant $d u$ front» renforcèrent la communauté nationale. Face aux difficultés matérielles, les livres, au ton de plus en plus moralisateur et performatif, eurent pour fonction de mobiliser matériellement les enfants à l'arrière. Dans ce contexte, des albums furent vendus au profit d'associations patriotiques. D'après les indications sur les prix et les tirages que nous avons pu trouver dans les archives de ces organisations et de la maison d'édition Schreiber, la littérature patriotique, probablement adressée aux enfants issus des milieux bourgeois, connut un certain succès.

\section{AUTEUR}

\section{BÉRÉNICE ZUNINO}

(Université Paris-Sorbonne/Freie Universität Berlin/IFHA, Francfort-sur-le-Main) 